\title{
AÇÃO EDUCATIVA JUNTO À EXPOSIÇÃO TEMPORÁRIA "A ESCRITA NO MUNDO ANTIGO"
}

A equipe de educadores da DDC/MAE vem trabalhando há alguns anos junto a exposições temporárias e/ou itinerantes montadas pelo MAE (assim como junto à exposição de longa duração "Formas de Humanidade"), em diferentes cidades do Estado de São Paulo e na capital paulista. Para tal foram estabelecidos alguns princípios, dentre eles: treinar/orientar professores e/ou monitores para atuarem como mediadores entre o público escolar e as exposições, a partir de uma proposta educativa (baseada nos princípios da Educação Patrimonial), e também, quando possível, trabalhar com escolares de diferentes faixas etárias, em monitorias organizadas e preparadas previamente.

A partir da exposicão temporária "A Escrita no Mundo Antigo", começamos a receber também grupos de pessoas não vinculadas diretamente à educação formal, ou seja, público da Terceira Idade e grupos formados esporadicamente.

O Projeto de Ação Educativa junto a essa exposição, montada no Centro Cultural Maria Antonia (CEUMA), da USP, foi elaborado com base nas experiências anteriores, mas com as especificidades que este tema exige, assim como com uma integração da equipe que elaborou o projeto expositivo. ${ }^{1}$ Desta prática surgiu muita troca de idéias possibilitando a melhor compreensão dos conceitos e de informações que queríamos comunicar através da exposição.

Neste trabalho foi muito importante a "ação articulada, embora não sistêmica, entre as atividades museográficas (desenvolvidas pèlo museógrafo Mauricio Cândido da Silva) e educativas (desenvolvidas pela educadora Judith Mader Elazari)" presentes nesta exposição sobre a "Escrita no Mundo Antigo"

Os objetivos gerais da Ação Educativa foram os seguintes:

Experimentar diferentes estratégias de ação educativa para exposições temporárias;

(1) Esta exposição foi produzida por um núcleo básico com a seguinte estrutura: Professora Dra. Haiganuch Sarian (coordenação científica), Professora Dra. Maria Cristina Oliveira Bruno (coordenação museológica), Maurício Candido da Silva (coordenação museográfica) e Judith Mader Elazari (coordenação educativa).
Refletir sobre a importância da escrita para diferentes povos do Mundo Antigo;

Apresentar ao público visitante a oportunidade de observar diferentes tipos de escritas do Mundo Antigo;

Oferecer dados para reflexão sobre o poder da escrita no Mundo Antigo e hoje;

Levantar polêmicas sobre escrita e oralidade;

Discutir alguns aspectos do processo de construção de conhecimentos sobre escritas antigas desde que seus vestígios foram encontrados até sua chegada ao museu.

Ao público escolar, de Terceira Idade e grupos especiais foram oferecidas atividades orientadas de acordo com a sua especificidade.

\section{Atendimento ao Público Escolar}

Trabalho de orientação para professores de Educação Infantil, Ensino Fundamental e Médio:

Consideramos fundamental o atendimento a professores, enquanto agentes multiplicadores Procuramos fornecer subsídios teóricos e metodológicos para que eles pudessem ampliar e aprofundar sua observação e seu conhecimento sobre o desenvolvimento da escrita no Mundo Antigo, assim como instrumentalizá- los para a realização de atividades com seus alunos junto à exposição, segundo os objetivos principais da ação educativa em museus. Todas estas expectativas vão de encontro à convicção de que os professores devem preparar seus alunos antes da visita ao MAE (ou a qualquer outro museu), deixando claro os objetivos da mesma e finalmente darem continuidade ao trabalho na sala de aula.

Assim sendo, foi organizado o Curso "A Escrita no Mundo Antigo: curso para professores de Educação Infantil, Ensino Fundamental e Médio" No decorrer do mesmo foram trabalhados alguns conceitos dos Parâmetros Curriculares Nacionais (PCN), principalmente transversalidade e interdisciplinariedade que se fundamen- 
tam "na crítica de uma concepção do conhecimento que toma a realidade como um conjunto de dados estáveis, sujeitos a um ato de conhecer isento e distanciado. Ambos apontam a complexidade do real e a necessidade de se considerar a teia de relações entre os diferentes e contraditórios aspectos (PCN, 1997).

O programa do Curso se relacionou também à Escrita propriamente e à Museologia $\mathrm{e}$ Educação em Museus.

Privilegiamos tanto as questões teóricas como as práticas, trabalhando com material pedagógico preparado para a expo-

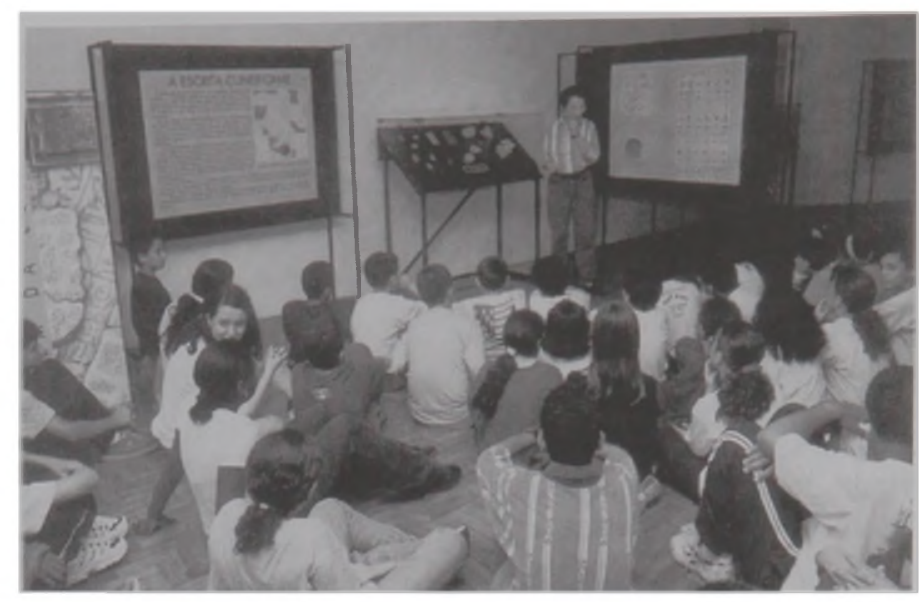

Fig. 1 - Monitoria para grupo de escolares na exposição. sição (textos, exercícios, gráfi-

cos, etc.) e tarefas em que o próprio professor era o sujeito das ações (exercício de Educação Parimonial, análise e interpretação de textos teóricos, criação de escrita própria, etc.). Entretanto, a orientação primordial dada a esses professores foi: "aprender a buscar, a ensinar, a conhecer" sem prescindir de uma liberdade de ação dentro do seu trabalho (Freire 1993).

Tendo em vista o reduzido número de visitas orientadas que a DDC/MAE poderia oferecer e o pequeno número de professores que compareceu ao Curso, considerou-se importante realizar também Treinamentos para Professores de curta duração, a fim de que pudessem conhecer a exposição e sua potencialidade pedagógica.

\section{Orientação para alunos de Educação Infantil, Ensino Fundamental e Médio}

Os alunos foram divididos em quatro faixas etárias (pré-escola e $1^{\mathrm{a}}$ série do E.F.; $2^{\mathrm{a}}$ série do E.F.à $4^{\mathrm{a}}$ série; $5^{\mathrm{a}}$ série à $8^{\mathrm{a}}$ série do E.F. e $1^{\mathrm{a}}$ à $3^{\mathrm{a}}$ série do E.M.) sendo que cada uma delas foi atendida de forma diferenciada.

O tempo de atendimento para cada visita foi de uma hora e meia. $\mathrm{O}$ número ideal de alunos para serem atendidos em atividades deste tipo é vinte cinco a no máximo trinta alunos, mas a realidade das escolas não o permite, pois há classes com até 50 alunos, o que prejudica o trabalho de apreciação e aprendizagem.

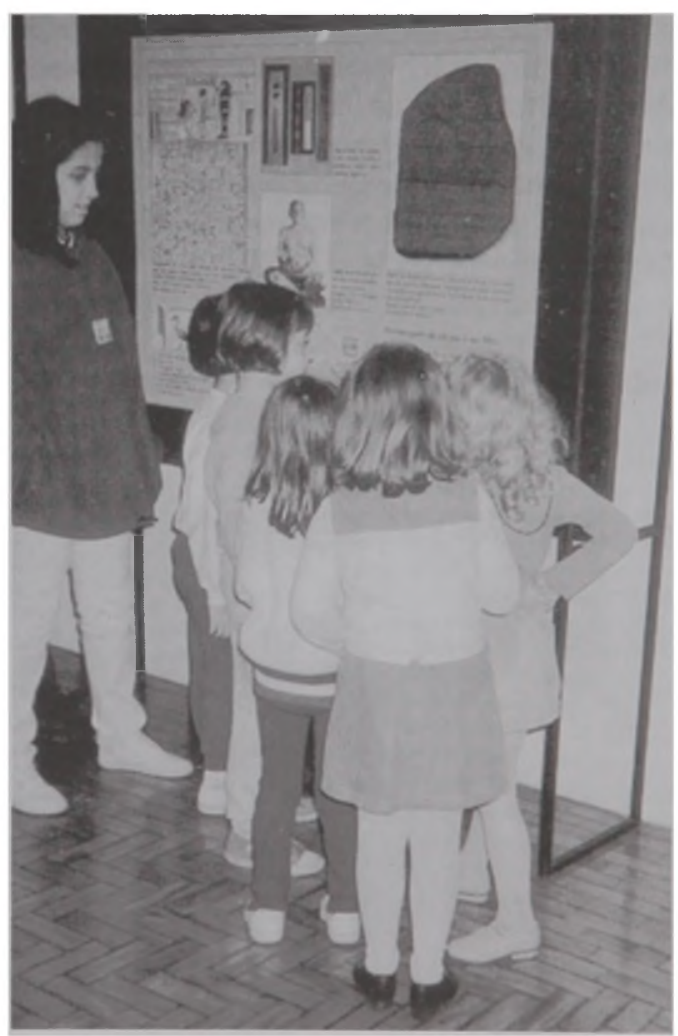

Fig. 2 - Crianças na exposição durante o "Ateliê da Escrita" realizado nas férias. 
A ação educativa junto a estes grupos teve as seguintes etapas:

- Acolhimento dos alunos em sala especial; para a sondagem sobre os conhecimentos já trazidos pelos alunos

- Visita à exposição, inicialmente livre e depois mediada por um educador

- Atividade final (oficina) fora da sala da exposição, servindo como síntese do trabalho realizado na exposição.

\section{Atendimento ao público da Terceira Idade}

Tendo em vista a importân-

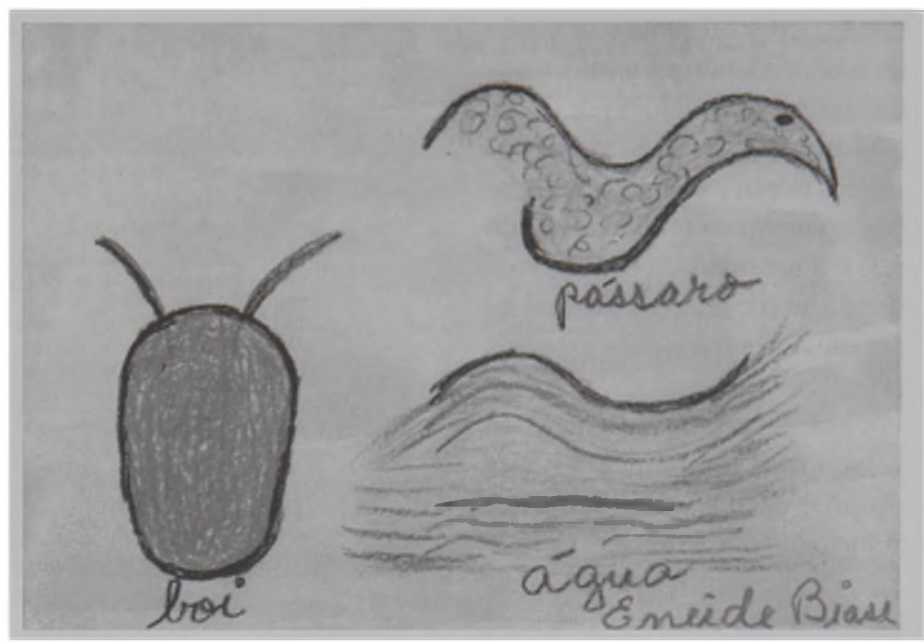

Fig. 4 - Desenho realizado por componente do grupo da Terceira Idade, durante oficina final. cia da diversificação de públicos a visitarem uma exposição, consideramos fundamental a presença de pessoas da Terceira Idade na Exposição "A Escrita no Mundo Antigo". Oferecemos três horários (um para cada mês em que a exposição esteve aberta). Somente a um deles houve o comparecimento de 15 pessoas, alunos do prof. Silvio Coutinho, no Projeto Lazer com Arte, do MAC/USP.

Esta atividade foi dividida em três etapas:

A primeira delas foi realizada em sala separada, onde houve o acolhimento dos visitantes e tro-

ca de idéias sobre algumas questões relacionadas à temática da exposição.

Na segunda etapa, o grupo foi à exposição e levou, segundo sugestão do professor Silvio, uma prancheta com papel e lápis para registrarem os signos que achassem mais interessantes, para depois trabalharem com eles.

Finalmente, a terceira etapa, foi uma oficina de desenho, em que utilizaram papel Canson e guache. Os participantes passaram para este papel os signos que haviam escolhido.

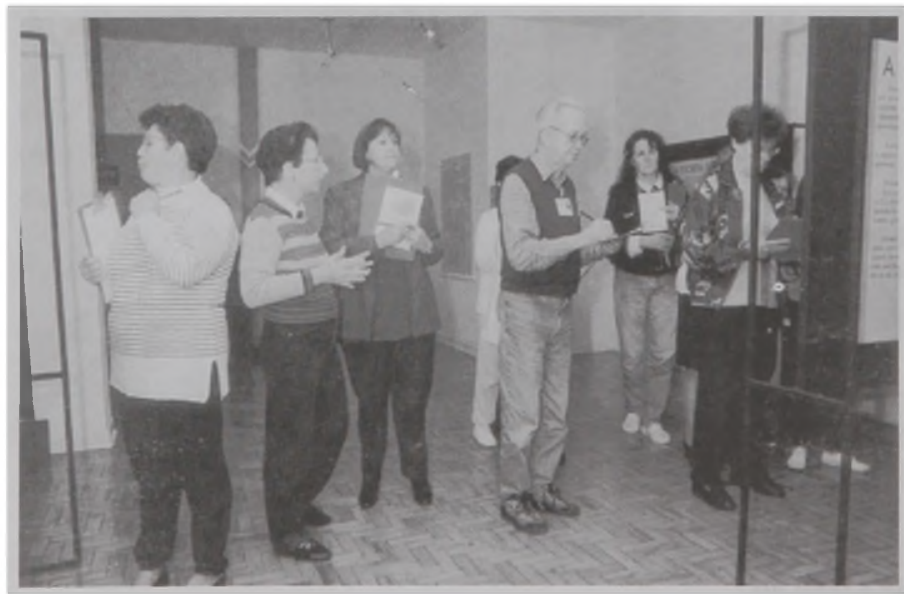

Fig. 3 - Grupo da Terceira Idade na exposição.

\section{Atividades informativas e lúdicas com público informal}

Estas atividades foram oferecidas durante as férias de julho, para público infantil e seus familiares.

O principal objetivo foi o de reunir diferentes gerações em atividades lúdicas e de lazer partindo-se de uma exposição temporária, além de dar a essas gerações conhecimentos para refletirem sobre a Escrita no Mundo Antigo.

Inicialmente trocaram-se idéias sobre a origem da escrita. 
Na sala de exposição eles transitaram livremente, conforme seus diferentes rítmos, com a mediação da educadora somente quando solicitada, diferentemente dos grupos anteriores em que havia esta interferência como objetivo da ação educativa.

Foram realizadas Oficinas tanto com desenhos como com argila
Esta experiência de ação educativa junto a uma exposição temporária nos abriu a possibilidade de realizar um trabalho de avaliação. Ao mesmo tempo, o trabalho conjunto de museografia e educação nos deu subsídios para reformulações nas próximas montagens desta e de outras exposições.

\section{Referências bibliográficas}

\section{FREIRE, $P$.}

1993 Professora sim, tia não. São Paulo, Ed. Olho d'Àgua.

1997 Parâmetros Curriculares Nacionais, vol. 8, Brasilia, MEC/SEF. 